\title{
Contribution evaluation of the maintenance plans based on reliability centered maintenance for measuring instruments in Public Higher Education Institutions
}

\author{
Rodrigo Schons Arenhart ${ }^{1}$, Morgana Pizzolato ${ }^{1}$, Angélica Alebrant Mendes ${ }^{1}$, Lynceo Braghirolli ${ }^{1}$ \\ ${ }^{1}$ Federal University of Santa Maria - UFSM, Santa Maria, RS, Brazil.
}

How to cite: Arenhart, R.S., Pizzolato, M., Mendes, A.A. et al. (2020), “Contribution evaluation of the maintenance plans based on reliability centered maintenance for measuring instruments in Public Higher Education Institutions", Brazilian Journal of Operations \& Production Management, Vol. 17, No. 2, e2020873.

https://doi.org/10.14488/BJOPM.2020.020

\begin{abstract}
Goal: implement maintenance plans based on RCM in a laboratory and identify difficulties in the preparation of a maintenance plan for measuring instruments of a calibration and testing laboratory.

Design / Methodology / Approach: Survey of the general maintenance scenario in PHEl laboratories, through individual interviews, and the implementation of maintenance plans elaborated from the implementation of Reliability Centered Maintenance (RCM).

Results: Adaptations of the maintenance activities carried out by the analyzed laboratory. A demonstration of the laboratory's great adherence to the ANBT NBR ISO / IEC 17025 standard, besides the possibility of improving the quality of the service.

Limitations of the investigation: The limitations are tied to the literature found on the subject and the application of maintenance plans restricted to only one university laboratory.

Practical implications: Improve the literature on maintenance plans and facilitate the practical elaboration of these plans by laboratories.

Originality / Value: Practical application of the preparation of maintenance plans for measuring instruments, not found in the literature of the subject.
\end{abstract}

Keywords: Reliability Centered Maintenance; Maintenance; Measuring Instruments; Laboratories.

\section{INTRODUCTION}

Measurement is present in many daily activities of humanity, in agriculture, livestock, commerce, industry and services. Measure is the experimental procedure by which the momentary value of a physical quantity (measurand) is determined as a multiple and/or a fraction of a unit, established from an internationally recognized standard (Albertazzi Junior and Sousa, 2015).

It is important to use the correct measuring instrument, since an inadequate measurement system can lead to problems such as: results with measurement uncertainty incompatible with the needs of the process; very frequent maintenance of measurement systems and shorter service life; difficult, expensive and/or time-consuming operation; difficult integration with computer systems; acquisition costs and/or high maintenance and calibration; poor or non-existent technical assistance; excessive misclassification in quality control or in process; poor final product quality (Albertazzi Junior and Sousa, 2015).

Financial support: None.

Conflict of interest: The authors have no conflict of interest to declare.

Corresponding author: rodrigoschonsarenhart@gmail.com

Received: 26 June 2019.

Approved: 7 May 2020.

Editor: Osvaldo L. G. Quelhas. 
Added to this, maintenance activities prevent the equipment and installation degradation caused by natural wear and tear. This degradation manifests itself in a variety of ways, such as bad external appearance of equipment, loss of performance and production stoppages, production of poor-quality products and environmental pollution (Xenos, 2014). Maintenance is defined as the combination of technical and administrative actions, including supervisory actions, designed to maintain or relocate an item in a state in which it can perform the required function (Associação Brasileira de Normas Técnicas, 1994). From this definition, it is clear that every effort should be made to ensure that equipment continues to perform the functions for which it was designed, at the expected performance level.

In this context, the extension laboratories of Public Higher Education Institutions (PHEI) must have maintenance practices for their measuring instruments, which are of various types of use, such as caliper rules, micrometers, spectrophotometer, scales, among several others. "The laboratory must have procedures to safely handle the handling, transportation, storage, use and planned maintenance of the measuring equipment, in order to ensure its correct operation and to prevent contamination or deterioration (Associação Brasileira de Normas Técnicas, 2017)." This makes clear the importance of retaining the measuring instruments in order to perform the tasks for which they were developed.

From the literature review, it is possible to verify the difficulty in developing a maintenance plan for measuring instruments. The maintenance literature addresses the topic of maintenance in a generic way and not using as an example measurement instrument. On the other hand, the metrology literature, which refers to measuring instruments only recommends that the maintenance should be done but does not present details of the elaboration of maintenance plans. Associated with this, PHEl laboratories managers are not always aware of techniques for preparing maintenance plans. Thus, the problem addressed by the present article becomes clear: how maintenance plans should be developed and managed for measuring instruments in test and calibration laboratories.

There is an increase in the number of calibration laboratories accredited by the General Coordination of Accreditation (Cgcre) of the National Institute of Metrology, Quality and Technology (INMETRO) in accordance with ABNT NBR ISO/IEC 17025 (Bender et al., 2017). This growth can be attributed other reasons, to the requirements of clients and government agencies such as Ministry of Agriculture, Livestock and Supply (MAPA), National Health Surveillance Agency (ANVISA) and Brazilian Institute of Environment and Renewable Natural Resources (IBAMA). Figure 1 shows the number of calibration laboratories accredited by Cgcre in Brazil from 2007 to 2010, 2016 and 2019 (Until June). It should be noted that the numbers from 2007 to 2010 were taken from the annual accreditation report, a document prepared by INMETRO, in 2010, the number referring to the year 2016 was collected from the article by Bender et al. (2017) and the current value was recorded from the INMETRO website.

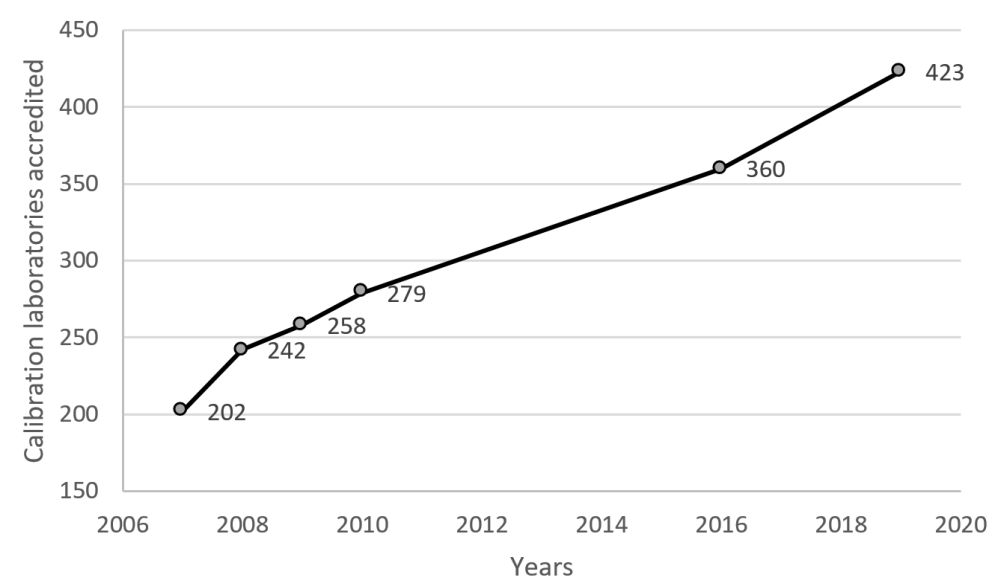

Figure 1. Number of calibration laboratories accredited by Cgcre in Brazil. Sources: Designed from the Annual Accreditation Report (2010) [[Q3: Q3]], Bender et al. (2017), \& Instituto Nacional de Metrologia, Qualidade e Tecnologia (2017). 
Laboratories that have a management system based on ABNT NBR ISO/IEC 17025 must have maintenance plans for their instruments, as well as maintenance records of the maintenance that was already made. The importance of designing an effective maintenance plan and its correct management is thus evident, which helps the test / calibration laboratory to meet the specifications of the offered services. The general objective is to implement maintenance plans based on RCM in a laboratory and identify difficulties in the preparation of a maintenance plan for measuring instruments of a calibration and testing laboratory.

\section{RELIABILITY CENTERED MAINTENANCE}

Reliability was included in maintenance planning activities through work on failures in military electronic equipment in the 1950s in the United States (Selitto, 2005). Many maintenance management practices were developed from a combination of corrective, preventive and predictive maintenance, generating an overall reduction in maintenance costs and increasing the availability and reliability of processes and equipment (Mendes and Ribeiro, 2011).

Every day people depend more on machines, which, however sophisticated, also show faults or breaks, making it impossible to use them (Souza, 2011). These types of equipment must perform the function for which they are designed and seek to avoid failures or be reliable over the projected time frame. The Reliability Centered Maintenance (RCM) seeks to assess the consequences of failures in a general way, aiming to increase availability, reducing costs and equipment repair times (Reis et al., 2012).

RCM is a systematic process used to determine what must be done to ensure that any physical installation can continually meet its required functions in its operational context. This methodology leads to a maintenance program that focuses preventive maintenance on specific failure modes that are likely to occur (Dhillon, 2002). The author present the main objectives of the RCM: (i) to develop priorities associated with projects that can facilitate preventive maintenance; (ii) gather useful information to improve item design with proven unsatisfactory reliability; (iii) develop Preventive Maintenance-related tasks that may restore reliability and safety in the event of equipment or system deterioration; (iv) achieve goals with minimum total cost.

Silveira et al. (2019) states that the main objectives of RCM-based maintenance are: (i) to preserve equipment functions with the required safety; (ii) restore reliability and designed safeguards; (iii) improve availability; (iv) minimize the life cycle cost; (v) act upon failure modes; (vi) perform only necessary activities; (vii) act on the effects and consequences of failure; (viii) document the reasons for choosing activities. Futhermore, the key benefits expected from implementing RCM can be summarized in reducing unnecessary preventive maintenance, reducing scheduled maintenance costs, increasing asset availability and equipment life, and reducing the number of spare pieces.

Maintenance costs are considered as a large part of the production system, where most of this cost is in unscheduled maintenance activities (Cavalcante and Costa, 2006). RCM is a technique that has been designed to achieve the best cost-benefit in the application of preventive maintenance, reducing costs by eliminating practices that are not extremely necessary to the process and focusing on the essential activities for the organization (Rausand, 1998). The author proposes steps to be followed to deploy RCM. Rausand's 12 steps for RCM deployment are described in Figure 2.

Other authors propose a very similar implementation methodology proposed by Rausand (1998), by modifying the number of steps, in the cases of Moubray (2000) and Smith (1993), seven steps were presented. This paper will make use of 5 steps for the implementation of RCM, described in section 4 (steps 2 to 6), based on the 12 steps of Rausand (1998), the division was done in 5 steps in order to make the application of the steps leaner and agile. 


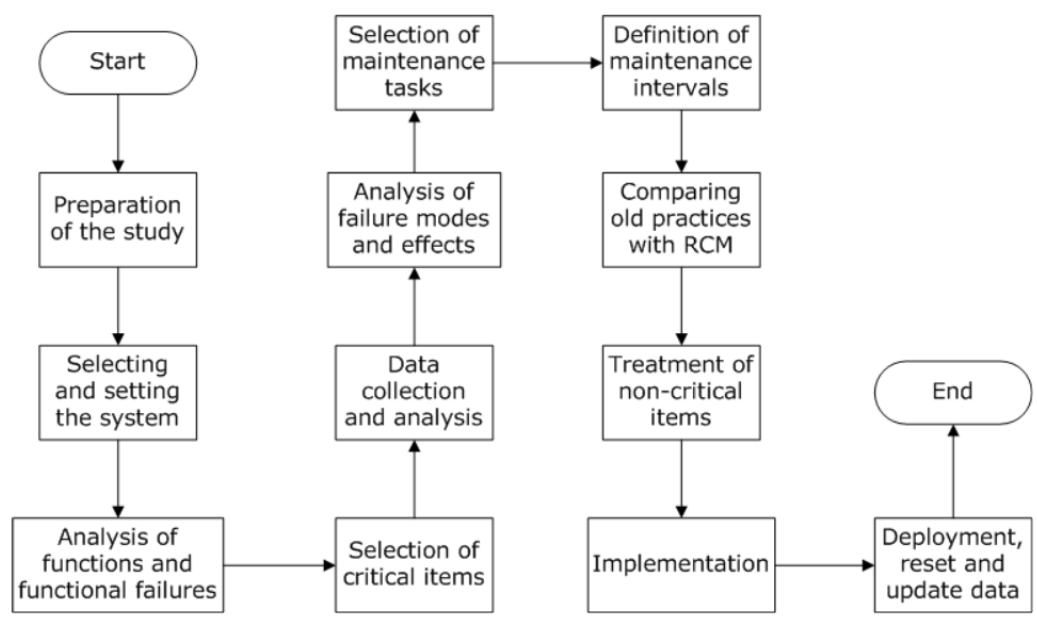

Figure 2. 12 Steps for RCM deployment. Source: Designed from Rausand (1998).

Deploying RCM enables to increase maintenance efficiency while maintaining system functions. The use of the Failure Mode and Effect Analysis (FMEA) tool, as well as variations, is recommended for the analysis of failure modes and effects (Mendes and Ribeiro, 2011). Quality assurance requires excellence in projects and processes. Excellence in design implies the potential for quality and excellence in processes turns the potential into real quality. For this, FMEA and FTA (Failure Tree Analysis) are techniques that help in the search for excellence. These techniques aim to identify weaknesses in the system and provide input for continuous improvement activities (Fogliatto and Ribeiro, 2009). The FMEA process development requires the definition of the scope, meeting with the work team, and verification of documents related to the process before beginning its application with the steps presents in the Figure 3.

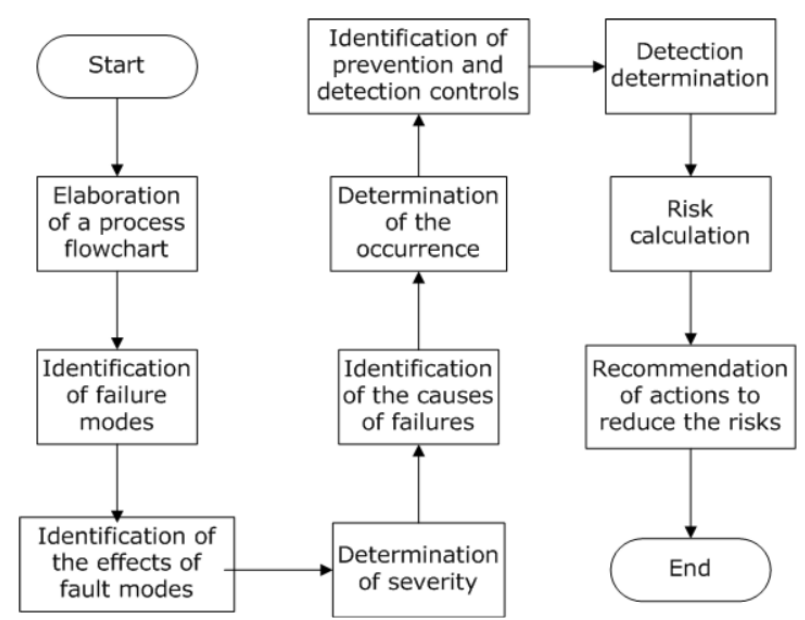

Figure 3. FMEA application steps. Source: Designed from Fogliatto and Ribeiro (2009).

Several authors present Decision Diagrams (DD) to determine the best maintenance strategies based on qualitative data of component failures, relating information regarding the evidence of failure, its consequences, prediction of wear and maintenance applicability (Mendes and Ribeiro, 2014). The use of the Logical Decision Tree (LDT) and DD in the task selection and maintenance interval selection step is appropriate because the LDT prioritizes failure modes that will use financial resources in the RCM process, while the DD helps specify the applicable and effective maintenance tasks (Zaions, 2003). 


\section{METHODOLOGY}

This section presents, in a first moment, the specific scenario where the research was carried out. Next, research method is identified, characterizing its nature, approach, objectives and procedures. At the end of this section are presented the steps of the research, as well as their specific descriptions.

\subsection{Study scenario}

The study in question contemplates two activities at two different levels; The first level, for broad research, will consist of PHEI laboratories, located at a federal university in the Rio Grande do Sul, Brazil. Unstructured informal interviews will be conducted by the researcher, with the person in charge (or their designee) of each selected laboratory. The importance of this first level is to list the maintenance practices adopted globally by the laboratories of the educational institution.

At the second level, the maintenance plans will be applied and will be carried out in a laboratory located at the university, linked to the Production Engineering and Mechanical Engineering courses. The objective of this level is the implementation of maintenance plans according to the RCM methodology. The laboratory is part of a quality management system, installed in a support body, with a set of technical-scientific laboratories that perform activities to provide specialized technical services with the management system developed by ABNT NBR ISO / IEC 17025. The laboratory conducts testing and calibration activities in the areas of strength, dimension and mass for teaching, research, and extension.

\subsection{Research method}

The research is characterized as applied, aiming at a practical application to solve specific problems of everyday life (Venanzi and Silva, 2016). The work intends to evaluate the difficulties of the elaboration and implantation of a maintenance plan and to identify its impact in an RCM calibration and test laboratory.

The approach is qualitative, since the concern is to obtain information about the perspective of individuals, as well as to interpret the environment in which the problem occurs (Miguel, 2010). The problem in question is in the analysed laboratory, where data collection and analysis are carried out.

As for the objectives, it can be defined as exploratory since it aims to provide a greater familiarity with the problem, making it more explicit or constituting hypotheses (Gil, 2002). It is also mentioned the explanatory characteristic, since it aims to identify factors that interfere or condition the occurrence of the phenomena (Boaventura, 2004). The lack of detailing in the elaboration of maintenance plans constitutes a problem for the work, through which, it is aimed to improve the existing knowledge. The project also hopes to monitor processes that can demonstrate the effectiveness of a maintenance plan.

In relation to the procedure, it is framed as action research, which is a type of empirical social research conceived and carried out in close association with an action or with the resolution of a collective problem, in which the researcher and the participants of the problem are involved in a cooperative or participative way (Thiollent, 2005). In this way, the data collection of the research was carried out in laboratories of higher education institution and the practical application of the research was carried out in a laboratory selected in this same institution.

\subsection{Research steps}

Part of the steps addressed in the methodology of this article (from the second step to the final stage) follow the definitions of the methodology proposed by Rausand (1998) that aims to implement RCM. Figure 4 presents the steps of the methodology employed in the research. 
1) Survey the situation of the university laboratories regarding maintenance: a interview form was elaborated and conducted in order to identify how the laboratories of the institution deal with maintenance. It was verified the existence of maintenance tasks, the kind of these tasks, who performs the tasks, how the periodicityand the control is made, actions on possible problems encountered, related costs, among others.

2) System Selection and Definition: The objective of this step is to select an analysis system that will assist in the implementation of the RCM. The global system was divided into subsystems; The subsystems that have significant functions for the process and that allow the analysis of their failure modes were selected.

3) Analysis of functions and failures, selection of critical items, data collection and analysis: this step aimed to identify and describe the expected functions of the system, in the specific case of the analysed laboratory, where a study was done identifying critical processes where the system can fail, and then selects critical system items to perform data collection and analysis.

4) Analysis of modes and effects of failure: we sought to identify the dominant failure modes of the analysis items identified, in addition to their causes of failure, their effects, consequences and criticality. This step was performed with the application of the FMEA process tool.

5) Task selection and definition of maintenance intervals: It was initially defined when the applications of preventive maintenance tasks are really necessary, applicable and effective. The periodicity of the maintenance tasks was then established based on the time, the failure rate, and the consequences of each failure. The selection was based on the data generated by the FMEA, among with the evaluation of the tools: LDT and DD.

6) Comparison of old practices and proposals by RCM: Finally, at this stage the research aimed to clarify the contribution of existing maintenance plans before the RCM evaluation and to suggest improvements to be applied in the system, as well as to verify the difficulties encountered in the development of this maintenance plan.

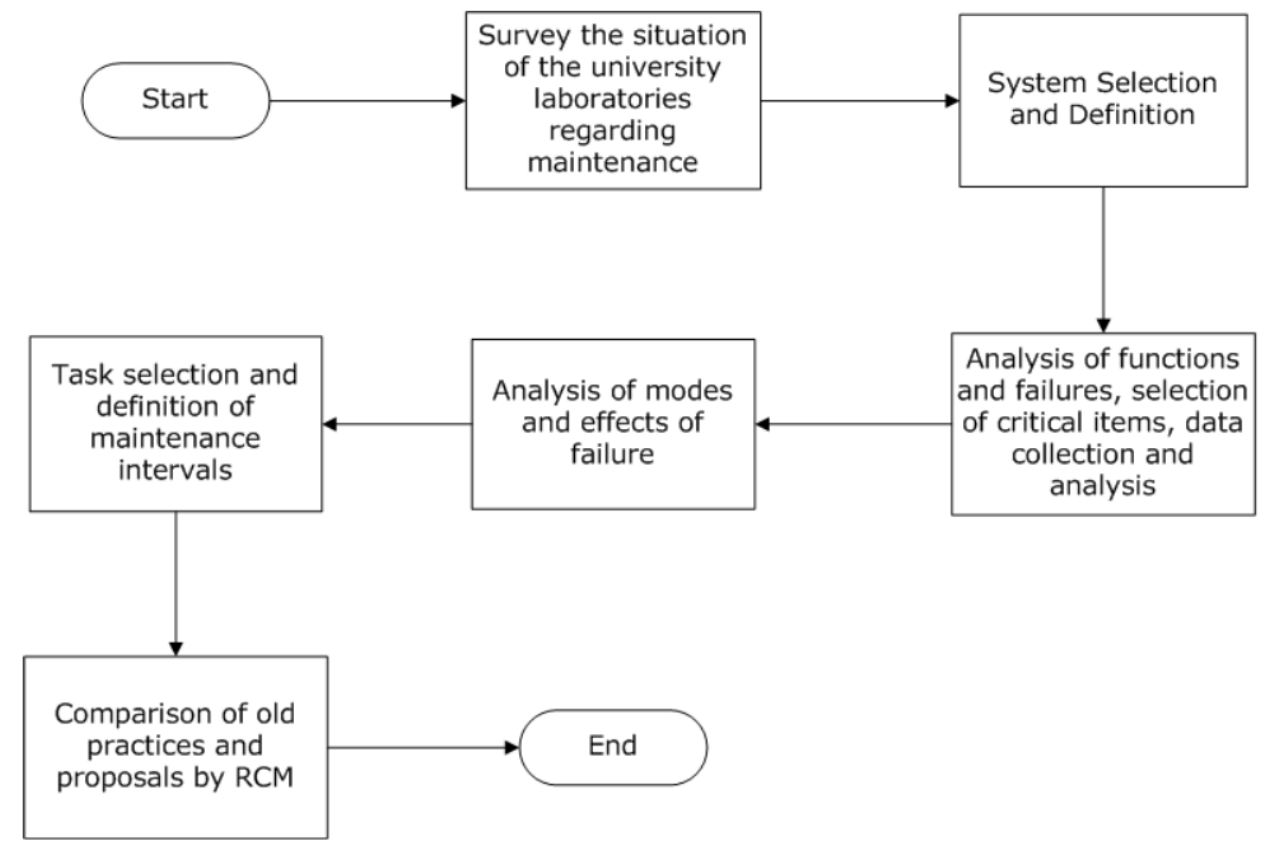

Figure 4. Research steps. Source: The authors themselves.

\section{RESULTS}

In this section the study results are presented and discussed. In the first stage, an overview of the laboratories situation in the educational institution was performed through individual interviews regarding to maintenance activities. Individual interviews have an 
essentially qualitative approach, where the number of interviewees is reasonably small and the interviewer's involvement is large, interacting directly with the interviewees (Ribeiro and Milan, 2007). The structure of the individual interviews is shown in Figure 5. Important interview points include the existence of maintenance activities in equipment, the need for outsourcing, the types of maintenance performed in each equipment, the frequency of their occurrence, and the existence of records.

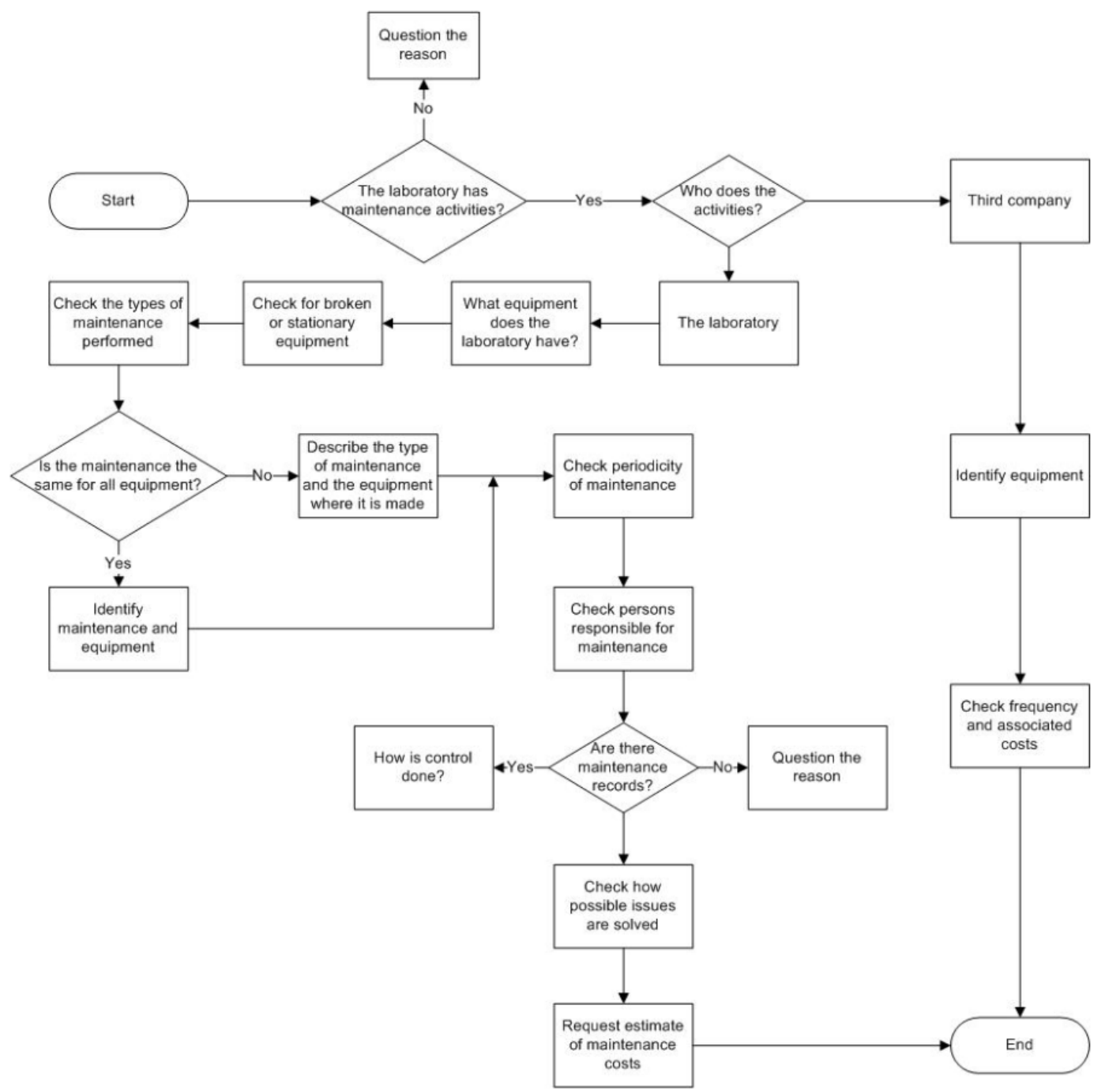

Figure 5. Structuring of individual interviews. Source: The authors themselves.

Seven managers and responsible for laboratories in the areas of chemical, mechanical (dimensional, force and mass) and calibrations in the dimensional and mass areas were interviewed. From the seven interviewees, two are accredited by the General Coordination of Accreditation (CCGRE) in accordance with ISO/IEC 17025, three are in the final phase of implementation of this standard, one uses the management system according to the standard, but is not accredited, and one does not have a formalized management system. It should be noted that all laboratories perform some maintenance activity. However, in some cases, there are neither records nor control. Table 1 presents general information about the studied laboratories related to area, time of activity, number of employees, accreditation, and number of equipment. The classification of the laboratory's activity area was made based on the nomenclature used by the State of Rio Grande do Sul Metrology Network. 
Table 1. General information about the laboratories.

\begin{tabular}{cccccc}
\hline Laboratory & Area & $\begin{array}{c}\text { Time of } \\
\text { activity }\end{array}$ & Employees & Acreditation & Equipment \\
\hline Lab A & $\begin{array}{c}\text { Testing of building } \\
\text { materials }\end{array}$ & 50 years & 30 & No & 67 \\
\hline Lab B & Chemical tests & 25 years & 15 & Yes & 35 \\
\hline Lab C & Chemical tests & 32 years old & 34 & No & 44 \\
\hline Lab D & Chemical tests & 25 years & 50 & No & 22 \\
\hline Lab E & Chemical tests & 19 years old & 12 & Yes & 39 \\
\hline Lab F & Chemical tests & 10 years & 10 & No & 54 \\
\hline $\begin{array}{c}\text { Analysed } \\
\text { laboratory }\end{array}$ & $\begin{array}{c}\text { Dimensional, force } \\
\text { and mass tests }\end{array}$ & 3 years & 10 & No & 73 \\
\hline
\end{tabular}

Source: The authors themselves.

Based on the research results, it was possible to observe that all laboratories use outsourced maintenance activities, since the equipment is usually of great complexity, making it difficult non-specialized teams perform maintenance. In this context, an annual value of maintenance costs is observed, ranging from US $\$ 1,500.00$ to US\$75,500.00. Another point to be reported is that the higher values are mainly concentrated in the chemical test laboratories that have equipment costing values up to US\$ $302,000.00$.

It was also possible to separate the equipment from the laboratories according to their use; some are frequently used while others are not operating, but in a working condition (available). Regarding the equipment under repair, there were two categories: (i) repair I, for equipment waiting for or receiving maintenance; (ii) in repair II, for equipment that can not be used and / or is not expecting to receive maintenance.

Among the interviews, all those in charge of laboratories stated that they have practices of internal preventive maintenanceand two laboratories said that they also perform corrective maintenance internally. From the interviews, it can be inferred that the maintenance in the accredited laboratories is not structured in a complete and adequate way, since they do not use consolidated methodologies such as Total Productive Maintenance (MPT) and RCM. The concern with this issue occurs only because it is a standard requirement. This can be verified in the maintenance records, giving that some laboratories have few records of equipment control and maintenance. It is important noting that the laboratoriesuse maintenance outsourcing for corrective maintenance, calling specialized teams as soon as they encounter a failure that can not be repaired by the laboratory personnel. In $86 \%$ of cases, laboratories do not have defined maintenance plans forequipment.

When comparing the laboratories interviewed with the analysed laboratory (laboratory in which the maintenance plans were elaborated), it can be seen that the latter has specific maintenance practices. The analysed laboratory also keep equipment records updated and accessible to all laboratory collaborators. Furthermore, the laboratory performs planned maintenance in the frequency defined in maintenance plans. Another important point is that, although not accredited, follows the requirements of ABNT NBR ISO/IEC 17025 standard regarding equipment handling, transport, storage, use, and maintenance activities.

To select the analysis system for implementation of RCM in the laboratory have identified equipment and standards that have significant functions for the laboratory. Thus, the laboratory was subdivided into 10 functional systems. The nomenclature of these systems does not characterize a specific physical item, but rather activities to be performed. The activities are calibrations and tests, since in the subsystems the main functions to perform the defined system procedure are identified.

The system selected for the study was the calibration of micrometers, since it corresponds to a large part of the measurements performed by the laboratory ( $42 \%$ of 
the total measurements in the year 2017) and has a consolidated procedure for its accomplishment. Between 2016 and 2017, 20 micrometer calibrations were performed. As the micrometer calibration procedure is a process, the study of this system must be done in all the equipment, standards and inputs used to perform it (standard blocks, cylindrical plain rings, optical parallels, isopropyl alcohol, anticorrosive, gloves, among others).

The defined subsystems of the chosen system were: (i) equipment, standard block and inputs selection; (ii) cleaning and lubrication activities; (iii) adjustment of measuring instrument; (iv) thermal stabilization; (v) measurements; (vi) seal measuring instrument and; (vii) protect and store equipment and standard blocks.

With the system and its subsystems defined in step 2, the functions of each subsystem were identified. The main function expected of the system is reliability in the micrometer calibration process. In this step (3), critical processes of the system were identified failures of its primary function were analyzed. The main physical items that comprise the micrometer calibration process were: anticorrosive, gloves, solvent, lubricating oil, cloths, standard block set, collection of optical parallels, enamel paint, isopropyl alcohol, and micrometers support. The physical items used in the micrometer calibration do not have manuals supplied by the manufacturers due to the simplicity of construction of the instruments, standards, and inputs used in their procedures. In this way, the laboratory team searched the recommendations for the accomplishment of the maintenances in catalogs of manufacturers and books.

This information generated the maintenance plan that was put into practice in the laboratory in 2016. This plan defined the maintenance activities to be carried out in equipment, where they should be performed, who should carry out the the activity, what tools and / or inputs and how often each activity should be carried out. This maintenance plan (prepared in 2016) encompassed all existing measuring instruments of the laboratory, which includes the subsystems that are the focus of this research. The control of the maintenance plan implemented in 2016 took place through three spreadsheets. The first one being a schedule of maintenance, presenting the weeks in which maintenance activities should be performed. The second describes the maintenance activities in equipment and the third is a history of the equipment, which includes all activities and occurrences related to it. In step 4, FMEA was used for the failure analysis of the micrometer calibration process. A flowchart of the micrometer calibration, inserted in Figure 6, was made to prepare the process FMEA.

The process FMEA was elaborated considering subsystems defined in step 3. We have identified 24 functions / operations, generating 118 combinations of mode and cause of failure, from which 25 are directly related to maintenance activities, corresponding to $21 \%$ of the total. Table 2 exemplifies one analyzed subsystem, already showing the improvement actions that were considered in the elaboration of the new maintenance tasks.

In order to perform task selection and to define maintenance intervals (step 5), the LDT and DD tools were used. The first aims to prioritize the failure modes that require financial resources in the RCM process, while the second aims to specify applicable and effective maintenance tasks. 


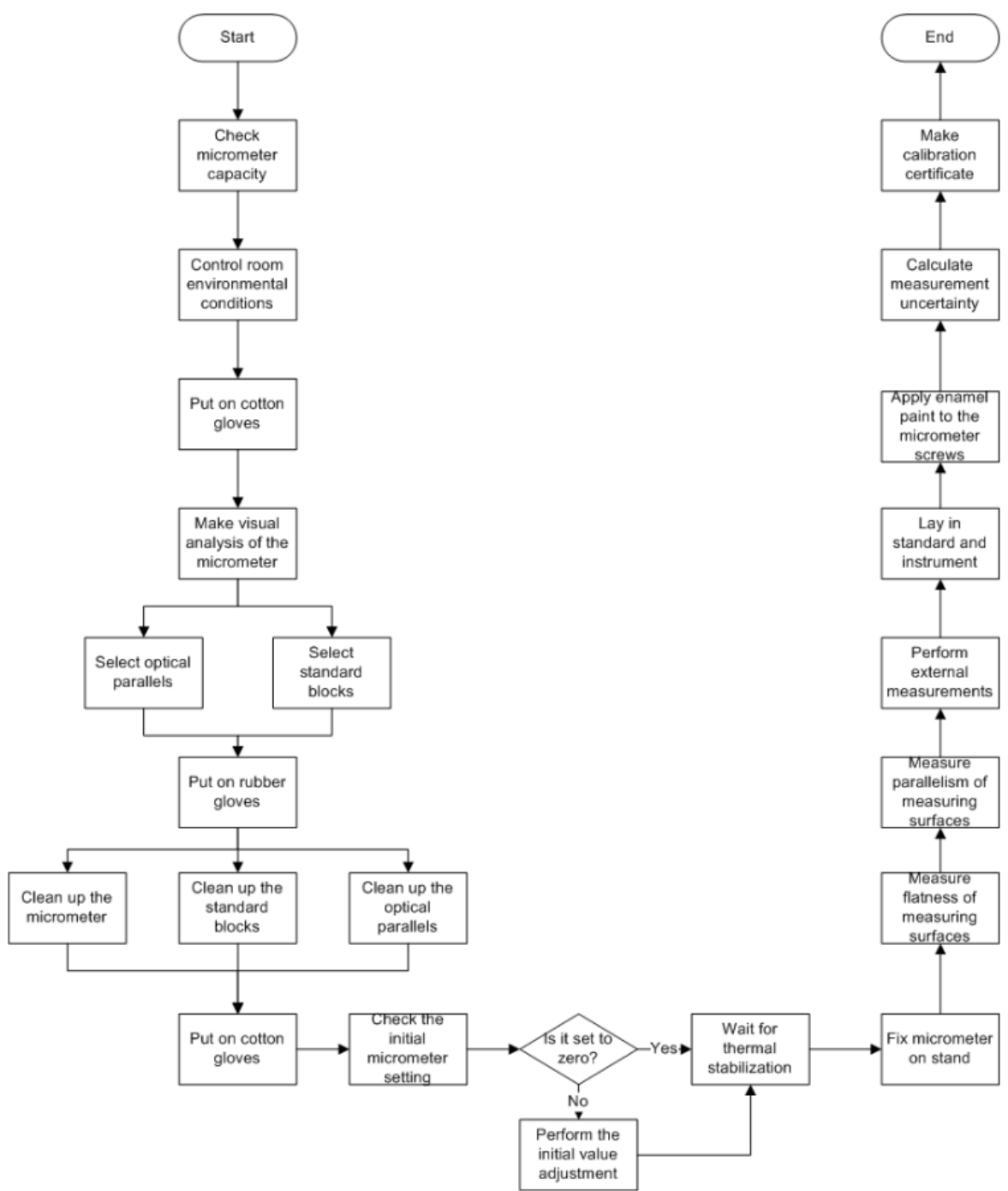

Figure 6. Micrometer calibration flowchart. Source: The authors themselves.

Based on LDT, it is possible to classify failure modes in four categories: (i) safety; (ii) environmental integrity; (iii) production downtime, and (iv) economic losses. LDT also allows for the identification of hidden failures in the analyzed process. When using the DD, the objective is to list all applicable maintenance tasks and select the most effective ones. If no task is selected, corrective maintenance is recommended.

Table 2. Subsystem example.

\begin{tabular}{|c|c|c|c|c|c|}
\hline Subsystem & $\begin{array}{l}\text { Physical } \\
\text { items }\end{array}$ & Failure mode & $\begin{array}{c}\text { Cause of } \\
\text { failure }\end{array}$ & Effect of failure & Improvement action \\
\hline \multirow{3}{*}{$\begin{array}{l}\text { Selection of } \\
\text { equipment, } \\
\text { standard } \\
\text { blocks and } \\
\text { supplies }\end{array}$} & $\begin{array}{l}\text { Standard } \\
\text { Blocks }\end{array}$ & $\begin{array}{l}\text { Select default } \\
\text { block } \\
\text { inappropriate }\end{array}$ & $\begin{array}{l}\text { Poorly } \\
\text { maintained } \\
\text { blocks }\end{array}$ & $\begin{array}{l}\text { Error in } \\
\text { measurement } \\
\text { result }\end{array}$ & $\begin{array}{l}\text { During maintenance, note which blocks are } \\
\text { oxidized and check which calibration } \\
\text { certificates have the smallest errors to update } \\
\text { the procedure }\end{array}$ \\
\hline & $\begin{array}{l}\text { Optical } \\
\text { parallels }\end{array}$ & $\begin{array}{l}\text { Select optical } \\
\text { parallels } \\
\text { incorrect. }\end{array}$ & $\begin{array}{l}\text { Poorly } \\
\text { conserved } \\
\text { parallels }\end{array}$ & $\begin{array}{l}\text { Error in } \\
\text { measurement } \\
\text { result }\end{array}$ & $\begin{array}{c}\text { During maintenance, note which parallels are } \\
\text { crossed out and check which calibration } \\
\text { certificates have the smallest error to update } \\
\text { the procedure }\end{array}$ \\
\hline & $\begin{array}{l}\text { Micrometer } \\
\text { support }\end{array}$ & $\begin{array}{l}\text { Select } \\
\text { inappropriate } \\
\text { support }\end{array}$ & $\begin{array}{l}\text { Poorly } \\
\text { maintained } \\
\text { media }\end{array}$ & $\begin{array}{l}\text { Difficulty in the } \\
\text { measurement }\end{array}$ & $\begin{array}{l}\text { Implement maintenance activities for } \\
\text { micrometer holders }\end{array}$ \\
\hline
\end{tabular}

Source: The authors themselves. 
All physical items of each subsystem were identified and evaluated according to their use in the subsystem. The failure modes present in the table indicate the possible causes of failure attributed to the process by the laboratory team together with the researchers, as well as the causes and effects of failures, where those with the highest risk index were prioritized.

The use of these tools supports the elaboration of actions to the maintenance plan. These actions were developed considering: (i) failure mode; (ii) its classification into one of the four categories expressed by the LDT; (iii) its possible maintenance tasks, according to the DD; (iv) the elaborated maintenance action; and (v) the frequency of the action. Table 3 presents the proposed actions for the subsystem "equipment selections, standard blocks and inputs" using LDT and DD.

From Table 3, it can be noticed that each failure mode presents one or more maintenance tasks, besides the determination of the respective frequency. The LDT column presents the classification of the problem found in the process, which is linked to one of the four categories previously mentioned. In DD space, it is verified the existence of eight occurrences: (i) routine task to avoid or evaluate the degradation level; (ii) knowledge of the relationship between age and reliability to failure; (iii) time-based restoration or disposal task; (iv) condition-based monitoring tasks; (v) failure mode association with hidden failure; (vi) functional verification tasks; (vii) effectiveness of the task and; (viii) elimination of failure mode and its effects through redesign. The answers to questions 1 to 8 is filled in Table 3 using " $Y$ " for yes and " $N$ " for no.

Table 3. Proposed actions for subsystem "equipment selections, standard blocks and inputs".

\begin{tabular}{|c|c|c|c|c|c|c|c|}
\hline \multirow[t]{2}{*}{$\begin{array}{c}\text { Sub } \\
\text { system }\end{array}$} & \multirow[t]{2}{*}{$\begin{array}{l}\text { Physical } \\
\text { items }\end{array}$} & \multirow[t]{2}{*}{$\begin{array}{l}\text { Failure } \\
\text { mode }\end{array}$} & \multirow{2}{*}{$\begin{array}{l}\text { Logical } \\
\text { Decision } \\
\text { Tree } \\
\end{array}$} & \multicolumn{2}{|l|}{ Decision Diagram } & \multirow[t]{2}{*}{ Action } & \multirow[t]{2}{*}{ Frequency } \\
\hline & & & & 1234567 & 8 & & \\
\hline \multirow{6}{*}{ 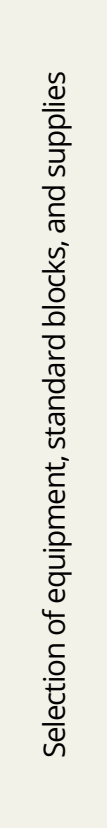 } & \multirow{2}{*}{$\begin{array}{l}\text { Standard } \\
\text { Blocks }\end{array}$} & \multirow{2}{*}{$\begin{array}{l}\text { Select default } \\
\text { block } \\
\text { inappropriate }\end{array}$} & \multirow{2}{*}{ Downtime } & \multirow{2}{*}{\multicolumn{2}{|c|}{$Y N-Y N Y Y$}} & $\begin{array}{l}\text { 1- Perform visual inspection to verify if the } \\
\text { standard blocks remain protected with } \\
\text { anticorrosive oil } \\
\text { 2- Visual inspect standard blocks and record } \\
\text { those that suffer oxidation }\end{array}$ & Weekly \\
\hline & & & & & $\mathrm{N}$ & $\begin{array}{l}\text { 3- Wipe using cloth wet with isopropyl alcohol } \\
\text { and dry using a dry cloth. Protect using } \\
\text { anticorrosive oil. Clean the excess of } \\
\text { anticorrosive using dry cloth, }\end{array}$ & Fortnightly \\
\hline & $\begin{array}{l}\text { Optical } \\
\text { parallels }\end{array}$ & $\begin{array}{l}\text { Select } \\
\text { incorrect } \\
\text { optical } \\
\text { parallels }\end{array}$ & Donwtime & $Y N-Y N N$ & $\mathrm{~N}$ & $\begin{array}{l}\text { 1- Perform visual inspection to record the } \\
\text { occurrence of scratches or wear } \\
\text { 2- Put a soft, dry cloth on the surface of the } \\
\text { optical parallels to remove dirt }\end{array}$ & $\begin{array}{l}\text { Fortnightly } \\
\text { Fortnightly }\end{array}$ \\
\hline & \multirow{3}{*}{$\begin{array}{l}\text { Micrometer } \\
\text { support }\end{array}$} & \multirow{3}{*}{$\begin{array}{l}\text { Select } \\
\text { inappropriate } \\
\text { support }\end{array}$} & \multirow{3}{*}{ dowtime } & \multirow{3}{*}{\multicolumn{2}{|c|}{ Y N }} & $\begin{array}{l}\text { 1- Disassemble and clean the support using } \\
\text { neutral detergent, brush, sponge and clean } \\
\text { cloths }\end{array}$ & Semester \\
\hline & & & & & & $\begin{array}{l}\text { 2- Lubricate the support using grease of general } \\
\text { use in its surfaces of slip }\end{array}$ & Semester \\
\hline & & & & & & $\begin{array}{l}\text { 3- Wipe using a cloth with neutral detergent on } \\
\text { the entire outer surface of the holder }\end{array}$ & Monthly \\
\hline
\end{tabular}

Source: The authors themselves.

It should be noted that, in addition to the actions related to maintenance activities, the process FMEA generated suggestions for improvement in the micrometer calibration process itself. These include update standard operating procedures based on calibration certificates of standard and parallel optical blocks, elaboration of instructional videos demonstrating how to perform activities considered more complex, performance of certain tasks in pairs or groups, and using protective materials for standards.

In step 6 a comparison was made between the old practices and those proposed by RCM. It was possible to observe that the maintenance plan currently used by the laboratory in the 
physical items of the analyzed process consists of preventive, predictive and corrective activities. Predictive maintenance seeks to guarantee the desired quality of service, based on a systematic analysis technique, using supervision or sampling to reduce preventive maintenance and reduce corrective maintenance (Reis et al., 2012).

The standards used in the process have individualized maintenance plans. In the case of the standard block set, there are activities of predictive maintenance (monthly visual inspection), preventive (cleaning and monthly lubrication) and corrective (removal of oxidations). The optical parallels have activities of predictive maintenance (biweekly visual inspection) and preventive (monthly surface cleaning). The support for micrometers and enamel paint had no plans for inspections and maintenance.

The elaboration of the maintenance plan based on RCMshows the importance of each item in the calibration process, since previously some items present in the process were not considered in the maintenance plans. It is worth mentioning the increment of eight new maintenance activities and the reformulation of three already existing activities in the maintenance plan. The new activities are: (i) carry out the adjustment of the initial value of the micrometer during the intermediary checks; (ii) adjust the air conditioning in the calibration room; (iii) register standard blocks that present oxidation; (iv) perform the cleaning of the blocks on EVA paper; (v) disassemble and clean the micrometer holder; (vi) lubricate the micrometer holder; (vii) wipe a cloth using neutral detergent in the micrometer holder and; (viii) verify the validity of the enamel paint used to seal micrometer screws. On the other hand, the activities that have been reformulated are: (i) cleaning and lubrication of standard blocks; (ii) visual inspection of optical parallels and; (iii) cleaning of optical parallels.

The implementation of new activities occurred due to the observation of the micrometer calibration process as a system. Physical items that were not present in the previous maintenance plans were considered as they play an important role for the system. The inclusion of new tasks for physical items that previously had maintenance plans, was due to the need to complement these plans. Three new tasks were developed for instruments that already had maintenance plans and the remainders were elaborated for items that did not have maintenance plans. The initial value adjustment of the micrometer was added to the plan because the laboratory did not perform previously intermediate checks, making the adjustments in the micrometers only in calibrations. The registration of blocks presenting oxidation was added because it assists in the elaboration of calibration procedures when it is defined which blocks are to be used in the process. The cleanliness and lubrication of the standard blocks on a surface protected by EVA paper is designed to provide protection against falling patterns.

Regarding to the reformulation of existing activities, it was verified the need for changes due to the conservation of the items and the effectiveness of the maintenance performed. In the case of standard block cleaning and lubrication over time, laboratory staff found that the standard blocks exhibited a loss of lubrication between maintenance periods, thereby activity from one month to 15 days. The visual inspection of the optical parallels was previously performed weekly, however, when checking risks in the parallels, there is no corrective maintenance activity by the laboratory team that can reverse this situation. The cleaning of the parallels, on the other hand, was frequently defined monthly, however, it was verified the need to increase the cleaning frequency as the pattern acquires dirt that can scratch it. Thus, both visual inspection and cleaning optical parallels had the frequency of verification and cleaning defined in fortnightly.

It was possible to verify that the implementation of RCM can generate improvements in the process in terms of quality of service. This can be verified by analyzing the aforementioned changes, where standard blocks were losing lubrication, which can lead to oxidation, and optical parallels were showing dirt, which could lead to surface scratches. The maintenance plan prepared in 2016 for the laboratory, did not follow the implementation stages of RCM. The result obtained in the 2017 plan highlights the importance of RCM methodology, since new maintenance activities were identified, and existing activities were modified Table 4 
presents the maintenance actions proposed using RCM to the standard block set physical item.

Table 4. Maintenance actions proposed using RCM.

\begin{tabular}{lrc}
\hline Physical Item & \multicolumn{1}{c}{ Task } & Frequency \\
\hline & 1) Perform visual inspection to verify if the standard blocks remain \\
protected by anticorrosive oil & Weekly \\
\cline { 2 - 3 } Standard Blocks Game & $\begin{array}{l}\text { 2) Record standard blocks presenting oxidation through visual inspection } \\
\text { 3) Clean the excess of anticorrosive using a dry cloth, then wipe using a } \\
\text { cloth moistened in isopropyl alcohol, dry using a dry cloth, and, finally, } \\
\text { protect using anticorrosive oil on the entire block surface } \\
\text { 4) Clean the blocks on EVA paper on the bench in laboratory room A }\end{array}$ & Weekly \\
& 5) Adjust the calibration room air conditioning & Fortnightly \\
\cline { 2 - 3 } & 6) Remove oxidation & Daily \\
\hline
\end{tabular}

Source: The authors themselves.

In order to carry out a comparison of the maintenance activities before and after the implementation of RCM, the numbers and frequencies of scheduled maintenance were compared. The total number of maintenance activities increased, from 9 to 18 activities. In addition, a new division was defined in the periodicity of some activities. While in the plans implemented in 2016 there were only activities with weekly and monthly frequency, in the new maintenance plans developed based on RCM we also have daily, biweekly and semiannual frequencies, showing more attention to activities based on time. The comparison of maintenance activities is verified in Table 5.

Table 5. Comparison of maintenance activities.

\begin{tabular}{ccc}
\hline Maintenance activities & Before RCM & After RCM \\
\hline Daily & 0 & 3 \\
Weekly & 2 & 2 \\
\hline Fortnightly & 0 & 4 \\
\hline Monthly & 5 & 5 \\
\hline Semester & 0 & 3 \\
\hline Corrective & 2 & 2 \\
\hline Time-based & 7 & 15 \\
\hline Based on condition & 2 & 3 \\
\hline
\end{tabular}

Source: The authors themselves.

During the preparation of the maintenance plan for measuring instruments in the laboratory, it was possible to identify some difficulties. The main difficulty was related to the lack of material related to maintenance plans, as was verified when analyzing the literature. Another aspect is the determination of the periodicity of the maintenance tasks, since the most part was determined based on the experience of the laboratory technical team. In addition, step 2 presented a marked difficulty, since the identification of the studied system was difficult to determine because it was a process and not a single instrument. It is also important to know all the steps and items comprising the micrometer calibration process, since it is a technical procedure that can be performed only by trained metrologists to correctly operate the measuring instrument and calibration standards.

It is possible to link the difficulties found in the elaboration of this study with the maintenance situation in other laboratories of the institution, as indicated by the survey of the maintenance scenario presented in the first stage of the project. The correct use of the tools (Flowchart, FMEA of process, LDT and DD) used in this study is very important for the elaboration of a maintenance plan, what can cause difficulties in other laboratories, since in 
many cases they do not have a prepared staff. Another issue is related to the little or no mastery of managers in maintenance plans, a fact that can make it difficult to structure maintenance practices in laboratories. In the general scope, it was verified that the accredited laboratories and in phase of accreditation follow the guidelines of the standard ABNT NBR ISO/IEC 17025 related to the maintenance. However, maintenance activities not individualized for each equipment and control of maintenance is not performed.

The time required to prepare the maintenance plans represents a significant factor to be analyzed since the work was carried out in approximately two years, being the first one to elaborate the plans of maintenance of each equipment belonging to the laboratory and the second one with the elaboration of plans of maintenance based on the RCM for the micrometer calibration process. This can be a challenge for laboratories, since it is necessary the participation of a team in a considerable interval of time, characteristic hardly found in the institution by the high turnover of people who make up the work teams of the laboratories, being mostly undergraduate and graduate students. Laboratories wich have permanent technicians are able to develop maintenance plans and put them into practice in an easier way.

Finally, it was found that the workload of the laboratory team will increase to implement the new maintenance plan, since the laboratory currently devotes $2.2 \%$ of the working hours of the month to maintenance activities related to the system studied and will need a future workload of $4.1 \%$. Note that the workload increased in the same proportion as the number of maintenance activities, as previously mentioned. To set the working hours in the month, two daily shifts of four hours and 20 days in the month were considered. Finally, the time for maintenance tasks were summed up and a maintenance time for ne new tasks were predicted.

\section{CONCLUSION}

This paper aimed to implement maintenance plans based on RCM in a laboratory. The analysed laboratory was compared with other laboratories of the same institution and verified the changes in the process provided by the maintenance plan based on the RCM. When comparing laboratories, it was also possible to verify that the analysed laboratory, even though it hasn't been accredited yet, was noted for following the requirements related to the handling, transportation, storage, use and maintenance of equipment of ABNT NBR ISO/IEC 17025, mainly, by the use of maintenance plans and updated equipment records. It has been found that the implementation of RCM-based maintenance plans can lead to process improvements in terms of service quality, where the life of the process components can be increased by providing a higher quality service to the laboratory customers.

The laboratory already had maintenance plans for some of the physical items (micrometers, standard blocks and optical parallels) and system components (micrometer calibration process) to which a new plan was made based on RCM. When comparing the RCM practices and the old practices, it was verified that the total number of maintenance activities have increased from nine to 18 (eighteen), as well as periodicities were defined based on daily, biweekly and semester frequencies, while in the old plan there were activities with weekly and monthly frequency only. These results correspond to the objective to implement maintenance plans in a laboratory based on RCM.

Throughout the work it was found a great difficulty to find materials to support the development of the implementation of maintenance plans. Another difficult point was the choice of the system to implement the plan according to RCM, because it is characterized by being a calibration process and not just a physical equipment of the laboratory. The difficulty of defining issues of periodicity of the new maintenance tasks and the characteristics of the chosen system is a difficulty to be solved by trained metrologists. In addition, the execution time of the work also configures in a difficulty found, taking 2 years for its elaboration and conclusion, which makes difficult the replication in other laboratories due to the high turnover of collaborators. The increase in the workload required for the execution of the plans is also cited as a difficulty, since the new maintenance tasks have practically doubled the time needed 
in relation to the tasks previously performed. With this, the objective of identifying difficulties in developing a maintenance plan for measuring instruments in a calibration and testing laboratory has been completed.

It was possible to link the difficulties encountered in the course of the work with the maintenance situation in other laboratories of the institution where it was perceived the importance of the correct use of the presented tools (Flowchart, FMEA of process, LDT and DD). In many cases they do not have staff with necessary knowledge. It was verified that the laboratories accredited and in the stage of accreditation follow the guidelines of ISO / IEC 17025 standard related to maintenance. However, the activities are jeopardized by the maintenance plans, are not individualized for each equipment, and also because do not perform the control of maintenance.

As a suggestion for future studies, other maintenance plans for measuring instruments are mentioned. Expand the study to other systems, in order to assist the development of the laboratory and the conservation of its equipment. Finally, to follow the changes proposed by the study and verify if the effects generated provide improvements to the laboratory. Also, from the failure data of the measuring instruments, perform reliability studies.

\section{REFERENCES}

Albertazzi Junior, A.G. and Sousa, A.R. (2015), Fundamentos de Metrologia Cientifica e Industrial, Manole, São Paulo.

Associação Brasileira de Normas Técnicas - ABNT (1994), ABNT NBR 5462: Confiabilidade $e$ Mantenabilidade, ABNT, Rio de Janeiro.

Associação Brasileira de Normas Técnicas - ABNT (2017), ABNT NBR ISO/IEC 17025: Requisitos Gerais para a Competência de Laboratório de Ensaio e Calibração, ABNT, Rio de Janeiro.

Bender, R.S., Pizzolato, M. and Albano, F. (2017), "ISO/IEC 17025: custos de acreditação em uma universidade pública brasileira", Exacta, Vol. 15, No. 1, pp. 1-14. http://dx.doi.org/10.5585/exactaep.v15n1.6526.

Boaventura, E.M. (2004). Metodologia da Pesquisa: Monografia, Dissertação, Tese, Atlas, São Paulo.

Cavalcante, C.A.V. and Costa, A.P.C.S. (2006), "Multicriteria model of preventive maintenance", Brazilian Journal of Operations \& Production Management, Vol. 3, No. 1, pp. 71-86, available at: https://bjopm.emnuvens.com.br/bjopm/article/view/32/pdf_28 (accessed 20 June 2019).

Dhillon, B.S. (2002), Engineering Maintenace: a Modern Approach, CRC Press, Boca Raton.

Fogliatto, F.S. and Ribeiro, J.L.D. (2009), Confiabilidade e Manutenção Industrial, Elsevier, Rio de Janeiro.

General Coordination for Accreditation (Cgcre). Accreditaion annual report. Rio de Janeiro, 2010.

Gil, A.C. (2002), Como Elaborar Projetos de Pesquisa, 4th ed., Atlas, São Paulo.

Instituto Nacional de Metrologia, Qualidade e Tecnologia - INMETRO. (2017), Laboratórios, available at: http://www.inmetro.gov.br/laboratorios/rbc/ (accessed 5 June 2019).

Mendes, A.A. and Ribeiro, J.L.D. (2011), "Um estudo do suporte quantitativo necessário para a operacionalização da MCC", Produção, Vol. 21, No. 4, pp. 583-93. http://dx.doi.org/10.1590/S010365132011005000032.

Mendes, A.A. and Ribeiro, J.L.D. (2014), "Estabelecimento de um plano de manutenção baseado em análises quantitativas no contexto da MCC em um cenário de produção JIT", Produção, Vol. 24, No. 3, pp. 675-86. http://dx.doi.org/10.1590/\$0103-65132013005000065.

Miguel, P.A.C. (2010), Metodologia de Pesquisa em Engenharia de Produção e Gestão de Operações, Elsevier, Rio de Janeiro.

Moubray, J. (2000), Manutenção Centrada em Confiabilidade, Aladon Ltds, São Paulo.

Rausand, M. (1998), "Reliability centered maintenance", Reliability Engineering \& System Safety, Vol. 60, No. 2, pp. 121-32. http://dx.doi.org/10.1016/S0951-8320(98)83005-6.

Reis, A.C.B., Costa, A.P.C.S. and Almeida, A.T. (2012), "Diagnóstico da gestão da manutenção em indústrias de médio e grande porte da região metropolitana de Recife", Produção, Vol. 23, No. 2, pp. 226-40. http://dx.doi.org/10.1590/S0103-65132012005000079. 
Ribeiro, J.L.D. and Milan, G.S. (2007), Entrevistas Individuais: Teoria e Aplicações, 2nd ed., FEENG/UFRGS, Porto Alegre.

Selitto, M.A. (2005), "Formulação estratégica da manutenção industrial com base na confiabilidade dos equipamentos", Produção, Vol. 15, No. 1, pp. 44-59. http://dx.doi.org/10.1590/S010365132005000100005.

Silveira, A.M., Vilseke, A.J., Pezzatto, A.T. et al. (2019), Confiabilidade de Sistemas, SAGAH, Porto Alegre.

Smith, A.M. (1993), Reliability Centered Maintenance, McGraw-Hill, Boston.

Souza, V.C. (2011), Organização e Gerência da Manutenção: Planejamento, Programação e Controle de Manutenção, 4th ed., All Print Editora, São Paulo.

Thiollent, M. (2005), Metodologia da Pesquisa-Ação. 14th ed., Cortez Editora, São Paulo.

Venanzi, D. and Silva, O.R. (2016), Introdução à Engenharia de Produção: Conceitos e Casos Práticos, LTC, Rio de Janeiro.

Xenos, H.G. (2014), Gerenciando a Manutenção Produtiva, 2nd ed., Falconi Editora, Nova Lima.

Zaions, D.R. (2003), Consolidação da Metodologia de Manutenção Centrada em Confiabilidade em uma Planta de Celulose e Papel, Dissertação de Mestrado em Engenharia de Produção, Universidade Federal do Rio Grande do Sul, Porto Alegre, RS.

Authors contribution: All the authors contributed equally to this paper. 